Article

\title{
Environmental and Cost Impact Assessment of Pavement Materials Using IBEES Method
}

\author{
Jin-Young Park ${ }^{1}\left(\mathbb{D}\right.$, Byung-Soo Kim ${ }^{2} \mathbb{D}$ and Dong-Eun Lee ${ }^{3, *(\mathbb{D}}$ \\ 1 Intelligent Construction Automation Center, Kyungpook National University, Daegu 41566, Korea; \\ jinypark@knu.ac.kr \\ 2 Department of Civil Engineering, Kyungpook National University, Daegu 41566, Korea; bskim65@knu.ac.kr \\ 3 School of Architecture, Civil, Environmental and Energy Engineering, Kyungpook National University, \\ Daegu 41566, Korea \\ * Correspondence: dolee@knu.ac.kr
}

Citation: Park, J.-Y.; Kim, B.-S.; Lee, D.-E. Environmental and Cost Impact Assessment of Pavement Materials Using IBEES Method. Sustainability 2021, 13, 1836. https://doi.org/ $10.3390 /$ su13041836

Academic Editor: Adelino Jorge Lopes Ferreira

Received: 13 January 2021

Accepted: 4 February 2021

Published: 8 February 2021

Publisher's Note: MDPI stays neutral with regard to jurisdictional claims in published maps and institutional affiliations.

Copyright: (c) 2021 by the authors. Licensee MDPI, Basel, Switzerland. This article is an open access article distributed under the terms and conditions of the Creative Commons Attribution (CC BY) license (https:// creativecommons.org/licenses/by/ $4.0 /)$.

\begin{abstract}
For road pavements, hot-mix asphalt (HMA) and Portland cement concrete (PCC) are the materials most commonly used. In the selection of one of these materials, their economic performance and environmental performance are evaluated to determine which material exhibits excellent overall performance. However, no overall performance assessment exists in the construction community attributed to the lack of method providing easy-to-use and informative criteria for the decision-making process. Thus, in this paper, a new method that enables a comprehensive overall performance assessment is proposed, which is called Improved Building for Environmental and Economic Sustainability. After an eco-economic life-cycle assessment is performed, along with environmental performance and economic performance evaluation, the best-fit pavement material can be selected. This method has proven that the use of HMA for road pavements reduces the environmental impact by $27.1 \%$ P (i.e., percentage point), whereas the use of PCC reduces cost by 19.7\%P. The existing Building for Environmental and Economic Sustainability (BEES) method shows that the performances of both HMA and PCC were over-assessed by $4.6 \% \mathrm{P}$ and $7.4 \% \mathrm{P}$, respectively, since the environmental performance and economic performance cannot be computed quantitatively by incorporating the environmental and cost impact index into existing BEES model, the Improved BEES method accurately projects environmental performance and economic performance attained through the application of the environmental and cost impact index, hence, encouraging more informed decision. This method facilitates in articulating a quality decision making through the consideration of both the environmental performance and economic performance, hence reducing unnecessary costs generated from the trial and error due to the use of the existing method. Moreover, it promotes the development of a sustainable construction technology.
\end{abstract}

Keywords: LCA; LCCA; environmental impact; cost impact; sustainable construction

\section{Introduction}

In Korea, road construction accounts for 33\% of the financial investments of the social overhead capital (SOC) [1]. Roads have a significant economic contribution and environmental impact. Among the stages of a road project, the paving stage accounts for the largest proportion (36\%) of the total environmental impact (except for bridge and tunnel constructions, which are considered as main road constructions). About $256 \%$ of the environmental impact is attributed to earthwork operations and $110 \%$ to the drainage processes [2]. After analyzing the economic and environmental impacts of hot-mix asphalt (HMA) and Portland cement concrete (PCC), Liu et al. [3] confirmed that the economic performance (ECP) and greenhouse gas (GHG) emission performance of the two materials differ by $7.4 \%$ and $26 \%$, respectively. Thus, the difference in the GHG emission performance is greater than that in the ECP. This indicates that in selecting the material for road pavements, the critical determinant that should be considered is the environmental performance (EVP) 
rather than the ECP. In addition, because pavement is the most expensive item in road construction, it is important to select a method that is more sustainable in terms of both cost and environmental impact [4]. Indeed, to select the best-fit material for pavement construction, an effective trade-off between the environmental and economic impacts is of great importance.

The selection of construction materials is commonly based on functional, technical, and financial considerations. However, the environmental impact attributed to sustainability, which has been a key issue in the last decades, is also an important criterion [5]. Generally, the sustainability of products or technologies is assessed based on social, environmental, and economic impacts [6]. In numerous countries, the assessments of economic feasibility and environmental impact are performed independently by conducting economic and technical reviews. For the economic review, the life-cycle cost analysis (LCCA) is employed, whereas for the environmental impact review, the guidelines for the life-cycle assessment (LCA) method formulated by the International Organization for Standardization (ISO) is employed. LCCA is mainly used by engineers for decision making, and the academia and regulatory agencies have focused on evaluating the environmental impacts of various alternatives [7]. In this regard, a mere analysis of economic efficiency without consideration of the environmental impact and environmental cost is not sufficient to achieve an informed decision making. While environmental impact is prioritized by some engineers over economic impact, numerous engineers have opposing opinions [8]. Currently, platforms for the evaluation of economic and environmental impacts of various construction materials are definitely lacking.

Construction stakeholders participate in the decision-making process. For the construction community, the ECP obtained via LCCA is a major concern. However, in the last decade, the sustainability associated with the EVP has become a key issue [5]. It is well accepted that construction projects have significant environmental impacts (e.g., pollution) due to the consumption of large amount of resources and energy. Thus, construction community is demanded to reduce such environmental impacts. Indeed, socioeconomic responsibility justifies the development of an integrated assessment method that evaluates both the EVP and ECP, each of which has different units of measure. Moreover, the development of a new method is desirable to identify the best alternative and to accurately reflect the impact of the EVP and ECP on the overall performance (OP). It may also enable the execution of trade-off between the EVP and ECP. Certainly, a tool that handles the issues in construction management does not exist.

The multi-attribute decision-making (MADM) method is appropriate for obtaining meaningful results in the OP assessment of the economic and environmental impacts of construction projects [9]. The Building for Environmental and Economic Sustainability (BEES) method, which was developed by the National Institute of Standards and Technology, USA, assesses the OP into a quantitative value using the MADM method. The BEES determines the relative excellence among the alternatives, rather than evaluating the exact OP of the economic and environmental impacts. The IBEES method has been developed and validated by analyzing the environmental and economic impacts of the candidate materials. It has been confirmed that by using such method, the best-fit construction material can be identified.

\section{Current State of the Environmental and Economic Impact Assessment Methods}

Sustainable development has become a major concern worldwide due to climate change. Construction projects emit a massive amount of environmental pollutants, including GHGs, while consuming three billion tons of raw materials or accounting for $40 \%$ of the world's raw material usage [10]. Nowadays, engineers are under continuous pressure to mitigate the environmental burden attributed to construction projects as merely reviewing the technical and economic feasibility does not satisfy the needs and expectations of the stakeholders for sustainability. Thus, numerous attempts to analyze the environmental impact of construction, particularly the environmental and cost impacts of the pavement 
materials used in road projects, have been made. However, to the best of our knowledge, no integrated method that takes into account both the economic and environmental impacts jointly each of which has different units of measure, has been developed to date.

Ma et al. [11] compared the resource consumptions and GHG emissions of both warm mix asphalt (WMA) and HMA using the LCA method. They found that these two materials consume similar amounts of resources; however, due to the lower mixing temperature, the WMA had less fuel burning and $\mathrm{CO}_{2}$ emissions than the HMA. WMA's GHG emissions were reduced by $46.7 \%$ compared to HMA, considering the production of asphalt compounds separately. The results indicate that, assuming comparable long term performances with that of HMA pavement, WMA pavement produces less $\mathrm{CO}_{2}$ emissions during their entire life cycle, which indicates that WMA pavement is friendlier for environment. They did not analyze the financial impact of WMA and HMA. To identify environmentally friendly materials for asphalt concrete, which is widely used for pavement construction, the LCA method is employed. By employing the LCA method, along with a midpoint method, Park and Kim [2] found that pavement construction has the greatest environmental impact in road construction. They identify the resources contributing to environmental degradation associated with HMA pavements and quantifies the environmental impact attributed to a $1-\mathrm{km}$ road construction. However, the limitation of Park and Kim [2] is incompetence in analyzing the financial impact. For sure, the LCA method does not lend itself to determine the correlation between the economic and environmental impacts attributed to the usage of alternative materials. Kwon et al. [12] estimated the environmental cost of pollutants per environmental impact category by measuring the environmental recovery fee using contingent valuation method. These results were used to represent the environmental impact that occur during the life-cycle of road projects as an expense. Kwon et al. [12] defined these costs as environmental costs. And they found that the biggest environmental costs were incurred during the construction stage. The weight of the construction stage was $83.5 \%$. Chan [13] evaluated both the environmental impact and economic feasibility by including the damage cost of pollution, which corresponds to the magnitude of environmental impact, as an external cost item in the life-cycle cost (LCC). According to this study, material production is the major source of energy consumption and greenhouse gases and pollutants emissions and there is the greatest environmental impact in the construction stage, where more than $80 \%$ of the materials are consumed. In addition, Kwon et al. [12] and Chan [13] evaluated the financial cost by comprehensively incorporating the cost items associated with environmental impacts into LCCA and converting environmental impacts into expenses. Thus, the soundness of these methods may appear to be dependent on the measure and application criteria for integrating the environmental impact into an economic outlook. Certainly, any finding obtained by these methods in the decision-making process of a project may not arrive at a full maturity of generalizability. The existing studies complement the lack of wellaccepted indicators which may facilitate in converting environmental impact into expenses by revealing the environmental and cost impacts associated with either the materials or construction methods. Indeed, the existing studies do not integrate both the environmental and cost impacts into an economic perspective. By jointly using both the LCA and LCCA methods, Liu et al. [3] assessed the environmental impact and economic feasibility of road pavements during their life cycles. After analyzing the case data, they found that a different solution may be obtained from the perspectives of cost and environmental impact, depending on the selection of different methods. In their study, the LCCA was $7.4 \%$ in favour of HMA. However, in the LCA, the GHG emission from PCCP was $26 \%$ less than the HMA over the 40-year analysis period. In addition, Li et al. [14] revisited the method hybridized with the LCA and LCCA methods. They confirmed that recycling the steel slag and coal fly ash in the construction of HMA pavement may reduce the energy consumption, GHG emission, and cost. Zhang et al. [15] applied the life-cycle optimization model, which was hybridized with the LCA and LCCA methods, to overlay systems with engineered cementitious composites, concrete overlay system, and HMA overlay 
system. They demonstrated that energy consumption, GHG emission, and costs can be reduced by $5-30 \%, 4-40 \%$, and $0.4-1.2 \%$, respectively. Using the environmental impact and economic assessment, Liu et al. [3], Li et al. [14], and Zhang et al. [15] identified the best-fit pavement material by comparing the performance outputs obtained from each evaluation. However, the best-fit pavement material they have chosen are biased results in terms of environmental impact or economic feasibility.

If the method used to evaluate either the economic or environmental impacts does not guarantee generalizability, it may not be suitable for multivariate decision making due to its inability to completely handle the two dimensions. Thus, several researchers have evaluated the generalizability of the MADM method, which has been employed in diverse decision making using different data attributes. Umer et al. [7] established a sustainability assessment model that evaluates the OP of pavement materials. They hybridized fuzzy composite programming (FCP) with the LCA and LCCA methods to identify the best alternatives by complementing the inaccuracy associated with limited data and/or empirical judgment. Moreover, it increased the reliability of the solutions, which may degrade due to inaccurate and/or ambiguous inputs in the initial phase of the project. However, the application of the FCP to eliminate uncertainty may make the evaluation algorithm somewhat complex, thus degrading its applicability. Sackey and Kim [8] modified the technique for order of preference by similarity to ideal solution (TOPSIS) method [16]. They also evaluated the OP of the roof materials of buildings, such as asphalt shingle and clay tile, using such method. This study contributes to the literature by providing an integrated assessment method that considers both the EVP and ECP using the proven MADM method (i.e., TOPSIS) in various fields. However, its validity is not supported by admissible evidence involved in the reliability of the model. Moreover, the BEES method [9] has identical issues involved in lacking method validation. The BEES method computed a $30.6 \% \mathrm{P}$ deviation between the OPs of the unfavorable alternative and the most favorable alternative. The EVP of the most favorable alternative was $117.3 \%$ of that of the unfavorable alternative, whereas the ECP of the most favorable alternative was $34.4 \%$ of that of the unfavorable alternative; hence, the expected OP difference was $59.6 \% \mathrm{P}$. However, this result does not guarantee the consideration of the EVP and ECP for the quantitative computation of the OP. Conversely, it confirms that the use of the TOPSIS method leads to the overestimation of the unfavorable alternatives. When the data used by Sackey and Kim [8] was input to the BEES method, the OP difference between the unfavorable and most favorable alternatives was $38.9 \%$. The difference decreased compared with the output obtained using the TOPSIS method. However, the use of the BEES method still led to the overestimation of the unfavorable alternative. Certainly, the existing MADM method guarantees generalizability in identifying a favorable alternative. However, the OP score itself does not assure generalizability, which enables exact quantitative comparison that is important to secure the reliability of information obtained by the method and to increase the usability of the method. It is not sufficient for engineers who design a facility to only determine the superiority of alternatives. Most engineers rely on practice and scientific background such as the MADM method in their decision-making process. However, the outstanding engineers who have extensive experience do not rely on the existing MADM method, when multiple alternatives are considered, but only qualitative evaluation can be used to accurately identify the performance ranking. Indeed, the performance ranking that can be extracted by experienced engineers using qualitative evaluation alone is not sufficient to provide an innovative integrated assessment method that enables trade-off between the EVP and ECP. Thus, the development of a new method that quantitatively considers the impact of the EVP and ECP on the OP, enables trade-off between the EVP and ECP, and identifies the best alternative is desirable. It may facilitate in setting goals quantitatively to reduce environmental or cost impact when upgrading unfavorable alternatives to the best ones. For this purpose, the new method called Improved Building for Environmental and Economic Sustainability (IBEES) may help save time and cost in developing a sustainable construction technology. 
With the growing awareness of the environmental issues, there is a need to incorporate environmental and cost considerations [17]. To address this issue, the construction community should develop and implement a systematic methodology for selecting building product that achieve the most appropriate balance between environmental and economic performance based on the decision maker's values [9]. In addition, information produced from this methodology should be quantified and synthesized so that it can be utilized to save costs and reduce environmental impact. To date, there is no study that comprehensively handles environmental and economic factors or integrates the environmental impact assessments using the LCA method and the economic assessments using the LCCA method. It has been found that the integrated assessment methods presented in some studies either lack generalizability or are difficult to use. Indeed, it would be desirable for an assessment method that integrates environmental and economic impacts to be able to derive reasonable results from an evaluation based on a method that guarantees generalizability using a simple computational process. In addition, to ensure the reliability and usability of such a platform, the simplicity of the process is important. If the outputs obtained by the method can be utilized to establish quantitative milestones for the development of eco-friendly technologies, it may significantly contribute to the development of eco-friendly technologies by reducing the socioeconomic costs caused by trial and error. This paper presents an integrated assessment method that provides accurate and widely acceptable information by complementing the limitations of the existing methods.

\section{IBEES Method}

\subsection{Assessing Environmental Performance Using the LCA}

Assessment of the EVP is performed using the ISO 14040 LCA [18] method. The LCA method can be employed to assess the inputs and outputs used or released during the production, transportation, use, and disposal of a product or service [19-21]. It is a "cradle-to-grave" approach that evaluates environmental impacts [22]. The term "cradle to grave" means that a product life ends in a landfill and the product is recycled into a new material [23]. The LCA is well accepted as the most favorable method that quantifies the potential environmental impacts attributed to a construction operation [24]. The procedures of the LCA method, presented in Figure 1, are as follows: (1) goal and scope definition, (2) inventory analysis, (3) impact assessment, and (4) interpretation [18]. The LCA is used in the IBEES method to calculate the EVP evaluation metrics for the HMA and PCC pavements. Consequently, the resources and energy consumption per a functional unit of $1 \mathrm{~km}$ in the construction and management stages of each pavement type are derived. The processes, resources, and energy consumption in the construction and maintenance stages are presented in Table 1 . They extracted from the unit price statement. The thickness of the HMA pavement is $63 \mathrm{~cm}$ (i.e., surface, $5 \mathrm{~cm}$; intermediate, $6 \mathrm{~cm}$; base, $23 \mathrm{~cm}$; and sub-base, $29 \mathrm{~cm}$ ), whereas that of the PCC pavement is $61 \mathrm{~cm}$ (i.e., slab, $26 \mathrm{~cm}$; base, $15 \mathrm{~cm}$; and anti-frost, $20 \mathrm{~cm}$ ). The use of asphalt in PCC pavements in the maintenance stage follows the maintenance scenarios [25] of the Korea Expressway Corporation (KEC), which include repaving of PCC using HMA per each 8 years after 20 years of usage, as presented in Table 2. The potential environmental impacts, which are expected based on the data presented in Table 2, are assessed using the life-cycle inventory database (LCI DB). The LCA is performed by using ecoinvent 3.0 [26] based on the National LCI DB [27] administered by the Korea Environmental Industry and Technology Institute. The midpoint method is well known to be relatively easy to access and interpret as it evaluates the impacts attributed to environmental damage by using daily language [28].

In Korea, eight potential impact items, which are generally applied to LCA using the midpoint method, are investigated. These are global warming potential (GWP), ozone depletion potential (ODP), abiotic resource depletion potential (ADP), acidification potential (AP), human toxicity potential (HTP), eco-toxicity potential (ETP), eutrophication potential (EP), and photochemical oxidant creation potential (POCP). 


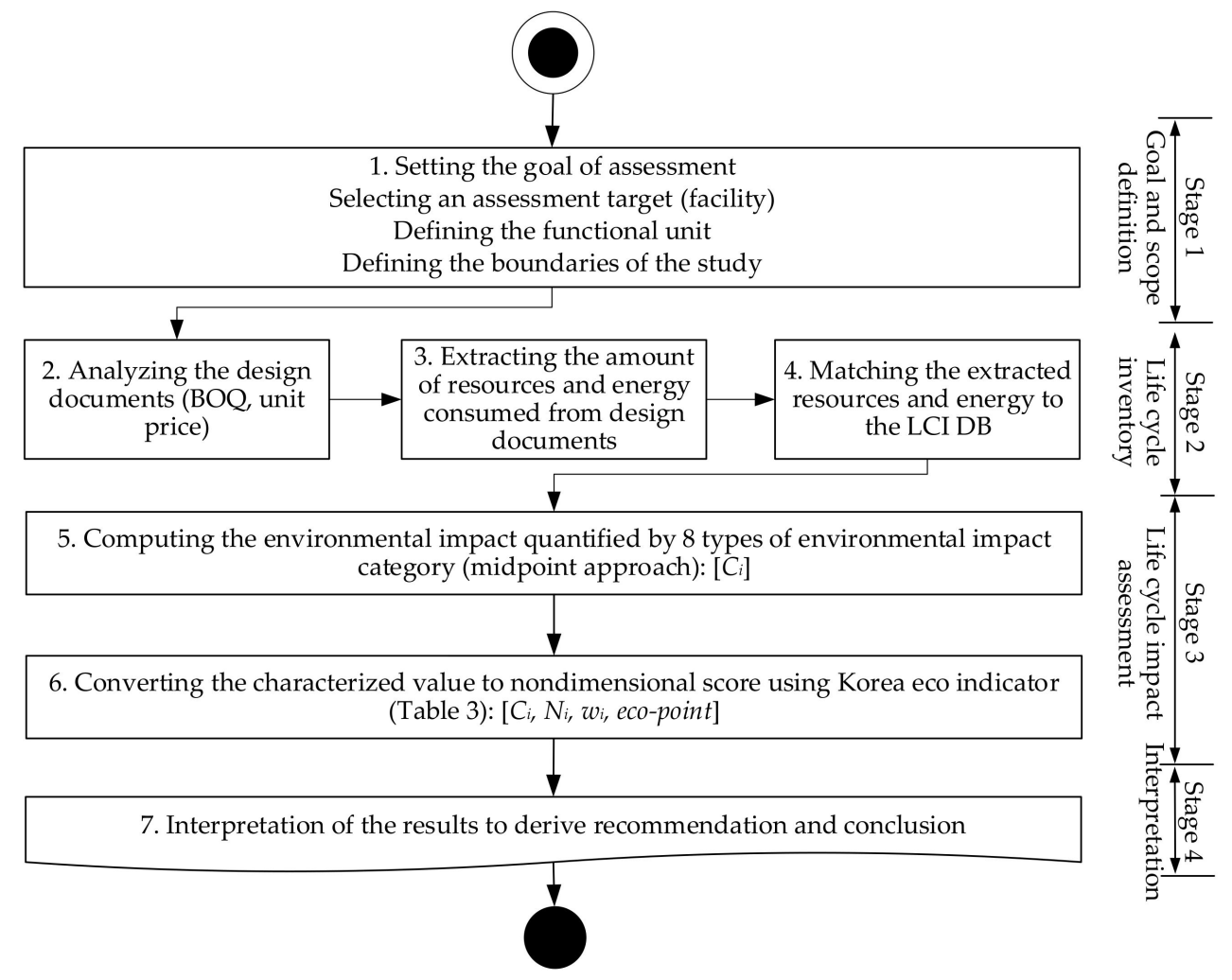

Figure 1. The LCA stages.

Table 1. The work process and resources under study.

\begin{tabular}{|c|c|c|c|c|c|}
\hline Method & Stage & Work Set & Major Resource & Quantity & Unit \\
\hline \multirow[t]{2}{*}{ HMA Pavement } & Construction & $\begin{array}{c}\text { Sub-base layer } \\
\text { Prime coat } \\
\text { Tack coat } \\
\text { Base layer } \\
\text { Intermediate layer } \\
\text { Surface layer }\end{array}$ & $\begin{array}{c}\text { HMA } \\
\text { Asphalt } \\
\text { Aggregate } \\
\text { Diesel }\end{array}$ & $\begin{array}{c}18,378.8 \\
24,624.6 \\
19,393,165.7 \\
211,130.9\end{array}$ & $\begin{array}{l}\text { ton } \\
\mathrm{kg} \\
\mathrm{kg} \\
\mathrm{kg}\end{array}$ \\
\hline & Maintenance & $\begin{array}{c}\text { Patching } \\
\text { Cutting and overlay }\end{array}$ & $\begin{array}{c}\text { HMA } \\
\text { Asphalt } \\
\text { Gasoline } \\
\text { Diesel }\end{array}$ & $\begin{array}{c}18,271.6 \\
129,254.6 \\
902.9 \\
213,227.9\end{array}$ & $\begin{array}{l}\text { ton } \\
\mathrm{kg} \\
\mathrm{kg} \\
\mathrm{kg}\end{array}$ \\
\hline \multirow[b]{2}{*}{ PCC Pavement } & Construction & $\begin{array}{l}\text { Anti-frost heave layer } \\
\text { Base layer } \\
\text { Slab } \\
\text { PE film spreading } \\
\text { Joint installation }\end{array}$ & $\begin{array}{c}\text { PCC } \\
\text { Aggregate } \\
\text { Gasoline } \\
\text { Diesel } \\
\text { Primer } \\
\text { PE film }\end{array}$ & $\begin{array}{c}9935.1 \\
13,965,273.3 \\
618.3 \\
7104.2 \\
11.1 \\
1068.2\end{array}$ & $\begin{array}{l}\mathrm{m}^{3} \\
\mathrm{~kg} \\
\mathrm{~kg} \\
\mathrm{~kg} \\
\mathrm{~kg} \\
\mathrm{~kg}\end{array}$ \\
\hline & Maintenance & $\begin{array}{c}\text { Crack repair } \\
\text { Joint repair } \\
\text { Cutting and overlay } \\
\text { Section repair } \\
\text { HMA Re-pavement }\end{array}$ & $\begin{array}{c}\text { PCC } \\
\text { Gasoline } \\
\text { Diesel } \\
\text { Epoxy } \\
\text { Primer } \\
\text { HMA } \\
\text { Asphalt }\end{array}$ & $\begin{array}{c}1231.3 \\
5655.6 \\
162,315.5 \\
5881.1 \\
22.3 \\
10,586.5 \\
74,573.4\end{array}$ & $\begin{array}{c}\mathrm{m}^{3} \\
\mathrm{~kg} \\
\mathrm{~kg} \\
\mathrm{~kg} \\
\mathrm{~kg} \\
\text { ton } \\
\mathrm{kg}\end{array}$ \\
\hline
\end{tabular}


Table 2. Repair scenario in the maintenance stage [25].

\begin{tabular}{ccccc}
\hline Method & Repair Work & Unit Price $\mathbf{( \$ / l a n e - k m )}$ & Cycle (Year) & Repair Rate (\%) \\
\hline \multirow{2}{*}{ HMA Pavement } & Patching & $44,915.3$ & 5 & 3.3 \\
& Cutting and overlay & $85,593.2$ & $6(9)$ & 100.0 \\
\hline & Crack repair & $53,389.8$ & 8 & 3.4 \\
& Joint repair & $20,339.0$ & 8 & 13.0 \\
\multirow{2}{*}{ PCC Pavement } & $47,457.6$ & 15 & 27.2 \\
& Cutting and overlay & $133,050.8$ & 10 & 20.2 \\
& Section repair & $219,491.5$ & 20 (once) & 100.0 \\
& HMA Re-pavement & $94,067.8$ & 6 & 4.2 \\
& HMA Patching & 79.661 .0 & 8 & 100.0 \\
\hline
\end{tabular}

When using the outputs obtained by the LCA method to decide which product to use, a single scoring (or weighting value) for all potential environmental impact items is crucial for a rapid decision making [29]. In addition, it is important to determine the importance weights of these items for a region (or country) due to the varying impacts of each item at each region [30]. The abovementioned method, which selects the best alternative, defines a single score to each and every environmental impact item. The lack of the single-scoring format may significantly increase the complexity of computation as each assessment of the potential impact category is cumbersome. Thus, the development of another method that combines the evaluation results of each environmental impact category is required. The Korean Eco-Indicator presented in Table 3 and Equation (1) is used to convert LCA outputs (i.e., the characterized values) obtained by the midpoint method to a non-dimensional eco-point.

$$
\text { EcoPoint }_{i}=\frac{C_{i}}{N_{i}} \times w_{i}
$$

where $C_{i}$ denotes the characterized value of the $i$-th environmental impact category; $N_{i}$, the normalization factor of the $i$-th environmental impact category; and $w_{i}$, the weighting factor of the $i$-the environmental impact category (Table 3).

Table 3. Eco-indicators [29].

\begin{tabular}{|c|c|c|c|c|}
\hline Impact Category & Unit & Normalization Factor $\left(N_{i}\right)$ & Weighting Factor $\left(w_{i}\right)$ & Converted Unit \\
\hline ADP & kg Sb-eq & 24.9 & 0.231 & \multirow{8}{*}{ eco-point } \\
\hline $\mathrm{AP}$ & $\mathrm{kg} \mathrm{SO}_{2}$-eq & 39.8 & 0.036 & \\
\hline $\mathrm{EP}$ & $\mathrm{kg} \mathrm{PO}_{4}{ }^{3-}-\mathrm{eq}$ & 13.1 & 0.038 & \\
\hline GWP & $\mathrm{kg} \mathrm{CO}_{2}-\mathrm{eq}$ & 5530.0 & 0.288 & \\
\hline ODP & kg CFC11-eq & 0.0407 & 0.292 & \\
\hline POCP & $\mathrm{kg} \mathrm{C}_{2} \mathrm{H}_{4}$-eq & 10.3 & 0.065 & \\
\hline ETP & kg 1,4 DCB-eq & 1.63 & 0.216 & \\
\hline HTP & kg 1,4 DCB-eq & 1480.0 & 0.105 & \\
\hline
\end{tabular}

\subsection{Economic Performance Using the LCCA}

The SOC accounts for a significant portion of the maintenance cost out of the total cost accrued during the service life of a road. Certainly, assessment of the project's economic efficiency based on the cost of the design and construction alone may only provide a partial view [31]. Thus, it would be desirable to assess the investment efficiency by selecting the most favorable alternative that achieves the lowest cost in the long term by using the LCCA method [32]. It may facilitate in verifying whether the high initial project cost may be justified by the maintenance cost over a long period. For this purpose, project owners use the LCCA method [22]. This study also uses the LCC obtained using Equation (2) as an ECP indicator.

$$
L C C=\text { InitCost }+\operatorname{MntCost}_{P V}+\operatorname{ReplCost}_{P V}+\text { ResdlValue }_{P V}
$$


where InitCost denotes the initial installation cost; $M n t \operatorname{Cost}_{P V}$, the present value $(P V)$ of the maintenance cost; ReplCost ${ }_{P V}$, the $P V$ of the replacement cost; and ResdlValue $P V$, the present residual value.

Frequently, road facilities are rehabilitated rather than being dismantled after their service life by overlaying new roads on the same route. That is why neither the dismantling cost nor the residual value is assumed to be retained at the end of the service life in LCCA. The operating cost and residual value at the end of the disposal phase of the facility were excluded from the maintenance cost expressed in Equation (2). The LCC was calculated using only the repair cost based on the criteria of the initial cost and the data in Table 1 , similar to that of the LCA calculation. In this study, the discount rate was derived by considering the inflation $(1.96 \%)$ and nominal interest rates $(4.60 \%)$ over the last decade (2009-2018), as provided by the Bank of Korea [33]. The real discount rate used for LCCA is $2.59 \%$ (i.e., $[\{(1+0.046) \div(1+0.0196)\}-1] \times 100)$. The analysis period was set to 50 years, which has been applied to the LCCA of road projects in Korea. Based on the maintenance scenario of the KEC, the repair cost at the maintenance stage was estimated and substituted in Equation (3) to convert it to the PV.

$$
L C C_{j}=\sum_{t=0}^{N}\left[\frac{C_{t}}{(1+d)^{t}}\right]
$$

where $L C C_{j}$ denotes the total $L C C$ for alternative $j ; C_{t}$, the sum of all the relevant costs occurring in year $t ; N$, the number of years in the study period; and $d$, the discount rate used to adjust the cash flow.

The integration of EVP and ECP may be defined as OP. The EVP is the equivalent weight value for representative materials, such as $\mathrm{CO}_{2}$, in each environmental impact category obtained by the LCA method. The ECP has monetary units in dimensions as it represents the total cost calculated using the LCCA method. Numerous researchers have attempted to integrate the EVP and ECP units, which have different dimensions, into monetary units to represent them as a single score. Moreover, some researchers use the price at which the representative materials for each environmental impact category were traded (such as the price of carbon allowance trades), whereas others use the costs that they are willing to pay to prevent (or recover) environmental pollution. However, the method of unifying dimensions into a monetary unit lacks the generalizability of the criteria for the determination of the unit price. This is due to uncertainties such as large fluctuations in the carbon allowance trading market. Some researchers have attempted to apply the MADM method to solve such uncertainties. The OP assessment using the MADM method is advantageous for guaranteeing the rationality and generalizability of the output results. However, it sometimes requires a somewhat complex process when used by project owners and designers. The underutilized assessment method of engineers is difficult to accept despite the theoretically good methodology. In light of this aspect, the study presented the BEES method [9], which was developed as a simple algorithm for the assessment of the EVP and ECP in construction projects, and the TOPSIS method [16], which was validated as a methodology for solving problems on the MADM method in various fields. The TOPSIS method was modified for the OP assessment using information of two attributes [8]. Subsequently, the results were analyzed to judge whether they provide information useful for the decision-making process.

\subsection{Overall Performance Assessment Using the TOPSIS Method}

The TOPSIS was developed upon the idea that a selected alternative should have the shortest distance from the positive ideal solution (PIS) and the farthest one from the negative ideal solution (NIS) [16]. It has been used by several studies as a MADM method owing to (1) its simplicity, rationality, and understandability; (2) its straightforward computation [34]; (3) its ability to define the relative performance of decision alternatives into a simple mathematical formula [35]; and (4) its broad recognition and application in 
the construction community [36]. The evaluation process of the TOPSIS is as follows: First, a weighted decision matrix using Equation (4) is constructed. To assess the environmental and cost impacts given identical conditions set to EVP and ECP, the weighting coefficient used 1. Next, the separation distance (SD) from the PIS and NIS of each alternative is measured. The validity of the TOPSIS to solve the problem on MADM has been confirmed by several studies. However, there is no other existing study that handles two attributes similar to the present study [8]. Therefore, the SD is defined by using Sackey and Kim's approach [8] presented in Equations (5) and (6). In that way, the TOPSIS is modified to incorporate the two attributes. Finally, the OP is calculated using Equation (7). In this method, a higher value of $\mathrm{Ci}$, which represents the OP score obtained using Equation (7), denotes a better alternative.

$$
\begin{gathered}
\text { NormalizedValue }_{\text {weighted }}=w_{i j} \times \frac{a_{i j}}{\sqrt{\sum a_{i j}^{2}}} \\
S i^{+}=\sqrt{\left\{\sum\left(V_{i j}-V_{j}^{+}\right)^{2}+V_{j \max }^{+} \text {for }\right\}} j=1 \ldots n \\
S i^{-}=\sqrt{\left\{\sum\left(V_{i j}-V_{j}^{-}\right)^{2}+V_{j \min }^{-} f o r\right\}} j=1 \ldots n \\
C i=\frac{S i^{-}}{S i^{+}+S i^{-}}
\end{gathered}
$$

where $\mathrm{Si}^{+}$and $\mathrm{Si}^{-}$denote the SDs from the PISs and NISs; $w_{i j}$, the weighting factor of $i$-th alternative $j$-th attribute information; $a_{i j}$, the value of $i$-th alternative $j$-th attribute information; $V_{i j}$, the weighted decision matrix; $V_{j}^{+}$and $V_{j}^{-}$, the PISs and NISs of $j$-th attribute information, respectively; and $C i$, the relative closeness to the ideal solution.

\subsection{Overall Performance Assessment Using the BEES Method}

The BEES method implements a systematic method for the selection of the best-fit construction materials (or products). Moreover, it performs the trade-off between the EVP and ECP and facilitates the identification of the optimal solution, taking into consideration both the ECP and EVP [9]. The OP score obtained by the BEES method is calculated using Equation (8). The EnvScore variable is based on the eco-points of the LCA results. In this study, each of them (i.e., OP score and EnvScore) is an EVP indicator. The LCC which presents the indicators of the ECP is employed. In the BEES method, the weighting coefficient of 0.5 is set for both the EVP and ECP to conduct a controlled experiment by holding the EVP and ECP identical $(E n v W t+E c o n W t=1.0)[9]$. As opposed to the TOPSIS, the smaller OP score is, the superior the alternative is.

$$
\text { Score }_{\mathrm{j}}=\left[\left(\text { EnvWt } \times \frac{\text { EnvScore }_{j}}{\sum_{j=1}^{n} \text { EnvScore }_{j}}\right)+\left(\text { EconWt } \times \frac{\text { LCC }_{j}}{\sum_{j=1}^{n} \text { LCC }_{j}}\right)\right] \times 100
$$

where Score $_{j}$ denotes the OP score of the $j$-th alternative; EnvWt and EconWt, the EVP and $\mathrm{ECP}$ weights, respectively $(E n v W t+E c o n W t=1) ; n$, the number of alternatives; EnvScore ${ }_{j}$, the LCA result of the $j$-th alternative; and $L C C_{j}$, the LCCA result of the $j$-th alternative.

The TOPSIS and BEES method implement a normalization process to convert attributes with different dimensions (i.e., EVP and ECP) to non-dimensional constants, thus comparing distances apart from the best value obtained by the best alternative on the Euclidean planes. The TOPSIS extracts the best value for each attribute from the decision matrix consisting of the EVP and ECP for each alternative, whereas the BEES method identifies the origin of the Euclidean plane as the best value. By employing the normalization process available in the BEES method, which is associated with the conversion of the EVP 
and ECP to non-dimensional constants, the new IBEES method accurately calculates the EVP and ECP impacts on OP.

\subsection{Implementing the Improved Overall Performance Assessment Model}

The IBEES method proposed in this study complements the limitations of the existing methods (i.e., TOPSIS and BEES) that do not consider the performance deviation between the EVP and ECP when assessing the OP. By introducing the concept of area on the Euclidean plane, the method normalizes the EVP and ECP, as presented in Equations (9) and (10). Then, each is defined to the environmental impact index (EI) and cost impact index $(\mathrm{CI})$, respectively. The BEES method retains the same concept as the existing BEES method.

$$
\begin{gathered}
I_{E j}=\text { EnvScore }_{j} / \sum \text { EnvScore }_{j} \\
I_{C j}=L_{C C} / \sum L C C_{j}
\end{gathered}
$$

where $I_{E j}$ denotes an EI for the $j$-th alternative; $I_{C j}$, the $C I$ of the $j$-th alternative; and EnvScore $j$ and $L C C_{j}$, the LCA (eco-point or characterized values) and LCCA results, respectively, for the $j$-th alternative.

The EI and CI of each alternative (i.e., A and B) are plotted on the Euclidean plane, wherein the $\mathrm{x}$-axis and $\mathrm{y}$-axis are EI and CI, respectively, as presented in Figure 2a. The environmental impact of alternative $A$ is smaller than that of alternative $B$ as much as $x$; moreover, the cost impact of alternative $A$ is larger than that of alternative $B$ as much as $y$. $\mathrm{A}$ and $\mathrm{B}$ are considered to be the best alternatives in terms of EVP and ECP, respectively. The OP is defined as the area of the EI and CI for each alternative, as presented in Equation (11). It is defined to the environmental and cost impact index (ECI). The ECI of A and B is enclosed in a rectangle labeled as "abef" and "cdeg", respectively, as presented in Figure 2a. The smaller the value of ECI, the more favorable the alternative.

$$
E C I_{j}=I_{E j} \times I_{C j} \times 100
$$

where $E C I_{j}$ denotes the environmental and $C I(\mathrm{OP})$ of the $j$-th alternative; $I_{E j}$, the EI of the $j$-th alternative calculated using Equation (9); and $I_{C j}$, the $C I$ of the $j$-th alternative calculated using Equation (10).

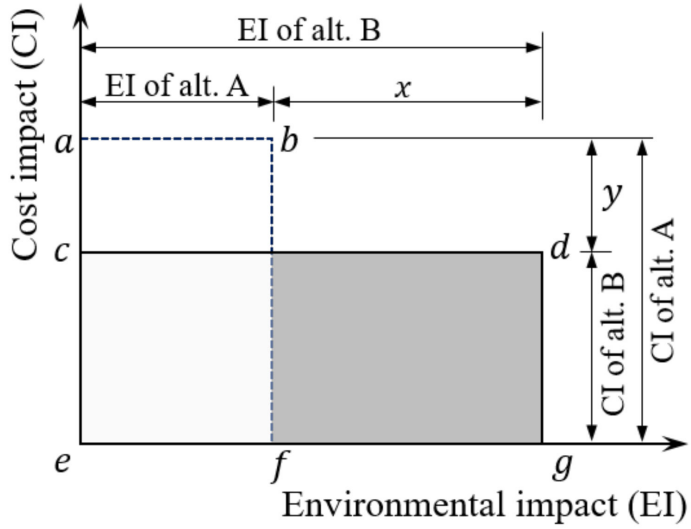

(a)

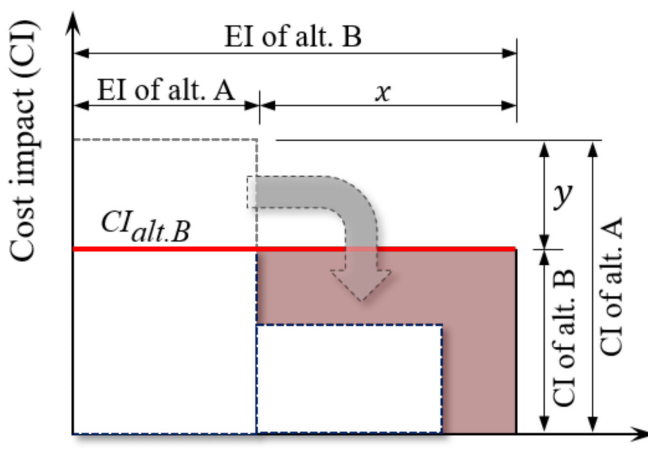

Environmental impact (EI)

(b)

Figure 2. The concept of the IBEES method: (a) EI and CI shown in Euclidean plane; (b) Overall performance expressed in a rectangular area formed by EI and CI.

The IBEES identifies the best alternative employing graphical computation as follows: For example, after the rearrangement of the $\mathrm{CI}\left(\mathrm{CI}_{\text {alt. }}\right)$ of alternative $\mathrm{B}$, as presented in Figure $2 b$, the shaded area is calculated. The ECI of alternative $B$ is as larger as the shaded area compared with that of alternative A. This confirms that the EI of alternative B is 
greater than that of alternative A when an identical cost is invested in the two alternatives. The ECI may correspond to the return on investment (ROI) incurred by both the EVP and ECP. Certainly, it is not questionable that alternative A can be accepted as the best solution. The shaded area presented in Figure $2 \mathrm{~b}$ represents the amount to which the EI of alternative B exceeds that of alternative A when fixing the CI. Conversely, the EI of alternative $B$ may be reduced while increasing the $C I$, as long as alternative $B$ retains the equivalent $\mathrm{OP}$ obtained by the best solution (i.e., alternative A) through the manipulation of compartment(s) consisting of alternative B. Thus, expressing the enclosed area by EI and CI into LCA output value (i.e., eco-point or characterized value) would be beneficial. It may also contribute to either the development of eco-friendly techniques or the improvement of the performance of the alternative. Using the linear relationship between the ECI and EI (or CI) on the Euclidean plane, the shaded area, which is called the margin of overall performance (MOP) obtained using Equation (12), may be represented as a percentage; hence, it can be used for the LCA outputs to obtain an eco-point (or characterized value) to reduce. The MOP is the minimum performance improvement necessary to replace an inferior alternative with a superlative alternative.

$$
M O P_{j}=\sqrt{\left(E C I_{o}-E C I_{j}\right)^{2}}
$$

The ratio of the MOPs to the ECI of alternative $\mathrm{B}$ is the marginal rate of overall performance (MROP) obtained using Equation (13).

$$
M R O P_{j}=M O P_{j} / E C I_{j}
$$

The minimum capacity for the environmental impact reduction (MCER), which ensures that the OP of alternative $B$ is equivalent to that of alternative $A$, is computed by multiplying the LCA result (i.e., eco-point or characterized value) by the $M R O P$, as expressed by Equation (14).

$$
\mathrm{MCER}_{j}=\text { EnvScore }_{j} \times \mathrm{MROP}_{j}
$$

where $M O P_{j}$ denotes the MOP of the $j$-th alternative; $E C I_{0}$, the OP of the best alternative; $E C I_{j}$, the OP of the $j$-th alternative; $M R O P_{j}$, the MROP of the $j$-th alternative; and $M C E R_{j}$, the MCER of the $j$-th alternative. Furthermore, EnvScore $j$ denotes the LCA results of the $j$-th alternative (eco-point or characterized value).

The MADM takes into account the percentage of significance of each criterion and reaches an acceptable/ satisfactory solution. And for this, various methods of decisionmaking are available; priority based, out-ranking based, distance based and mixed methods [17]. The modified TOPSIS [8] and the BEES [9] used in existing studies to synthesize environmental impact and economic feasibility assessment are based on separation distances. Surely these methods are useful in finding favorable alternatives. However, to save costs and reduce environmental impacts, they failed to use information that combined the results of environmental impact and economic feasibility. Both methodologies assumed that environmental impact and economic feasibility were independent objects. This means that it does not affect the results of each other's assessment. The methodology proposed in this paper defined the combined evaluation results (i.e., OP) as the area of the rectangle in which the two variables form. Environmental impact and economic feasibility affect each other. It ensures that environmental and cost impacts are quantitatively expressed in OP. Surely this information complements decision making that balance environmental impact and economic feasibility. In addition, it provides useful information to save costs and reduce environmental impact.

\section{Method Verification}

The method is verified in three phases. First, the EVP and ECP of the HMA and PCC, which are the most commonly used pavement materials, are analyzed in their entire 
life cycle, and the OP is evaluated using the MADM method. The EVP is evaluated by conducting the LCA administered by ISO 14040 [18]. This case study quantifies the environmental impact of the materials and the energy consumed by pavement construction. Conversely, the ECP is measured using the LCCA method, which is well accepted for the economic analysis of construction projects. Through the application of the method to national highway projects previously mentioned, in which the HMA and PCC pavements are planned at the initial stage of the design, the economic analysis outputs were obtained. This confirms that PCC, of which the LCC is $89.7 \%$ of that of HMA, is economically more favorable. To conduct a controlled experiment and analysis using the LCA and LCCA methods, only the data associated with the scope of this study are extracted from the design data of the case projects. For example, the material-specific characteristics attributed to each of the two pavement materials are clearly separated through elimination of the data associated with other processes (i.e., installment of median strip, placement of drainage facilities, and marking of lanes). Both the administrative-side and user-side operations are excluded from the maintenance phase. However, only the repair and replace are considered for the administrative side. The repair and replace items are adopted from the scenariobased data [25] administered by the KEC to be used for the LCCA of road construction projects. At the second phase, the validity of the proposed method is confirmed with the use of qualitative indicator. The qualitative indicators confirm that the outputs (i.e., the favorable alternative) obtained by the IBEES method is equivalent to those obtained by the modified TOPSIS and the BEES methods. If the TOPSIS and BEES methods, which are well accepted as decision-making tools, obtain outputs different from those obtained by the IBEES method, the new method may not be valid. At the third phase, the effectiveness of OP assessments obtained by the BEES and TOPSIS methods is estimated with the use of quantitative indicator. The quantitative indicators accurately denote the EVP and ECP impacts in a single score. When developing a new eco-friendly construction method or upgrading the existing ones in eco-friendly attributes, the fulfilling of EVP alone is not sufficient for practice. Both the EVP and ECP should be excellent over comparison targets. Thus, an OP assessment with admissible evidence is essential. In the selection of the optimal construction method, not only the relative excellence but also the impact of the EVPs and ECPs should be quantitatively evaluated. For this purpose, the method confirms that the OP obtained by the BEES and TOPSIS methods can represent the impact of the EVP and ECP, hence proposing an improved OP assessment method. If the IBEES method passes the tests using qualitative and quantitative indicators, the IBEES method has the potential to increase the accuracy of decision making involved in the optimization of the environmental and economic impacts of the project.

In this study, two road pavements, which have the same size and number of lanes, are utilized to confirm the validity and effectiveness of the IBEES method. They are the national highway projects of South Korea with a standardized total extension of $1 \mathrm{~km}$ to ensure the ease of operation and consistency in the analysis. The first and second cases are the HMA and PCC pavements, respectively. The scenario-based data presented in Table 2, which were administered by the KEC, are utilized in the maintenance stage in the LCA and LCCA.

\subsection{Evaluating Environmental Performance}

The LCA outputs attributed to the HMA and PCC pavements at the construction phase are 359 and 659 eco-points, respectively, as presented in Table 4 . The former is $83.6 \% \mathrm{P}((659-359) \div 359 \times 100)$ greater than the latter. This indicates that PCC has higher environmental impact compared with HMA. According to the maintenance scenario [25] presented in Table 2, PCC road is repaved with HMA 20 years after the completion of the construction. When applying the PCC pavement, the "cutting and overlay" and "section repair" maintenance should be implemented every 15 and 10 years, respectively. However, the implementation of these two maintenance activities is not required after the PCC road is repaved with HMA. This indicates that these two maintenance activities are implemented 
only once during the entire life cycle of the road facility (i.e., 50 years). Despite the repavement of HMA after 20 years of use, the cutting and overlay operation is required four times, including HMA overlays, every 8 years. Meanwhile, for the HMA pavement, seven cutting and overlay operations are required over a 50-year period. The cutting and overlay as well as the section repair are tasks that are expected to have a relatively significant environmental impact. However, in terms of the repair rates, the PCC pavement is $100 \%$ for only HMA re-pavement after 20 years of use, whereas "cutting and overlay" and "section repairs" are $27.2 \%$ and $20.2 \%$, respectively. Indeed, the maintenance scenarios of the KEC are configured to indicate that the PCC pavement has a better performance compared with the HMA pavement in terms of the number of operations and workload required; thus, the environmental impact of the HMA pavement was evaluated to be higher by $17.6 \% \mathrm{P}$ $((320-272) \div 272 \times 100)$ in the maintenance stage.

Table 4. LCA outputs (kg).

\begin{tabular}{|c|c|c|c|c|c|c|c|c|c|c|}
\hline \multirow{2}{*}{ Material } & \multirow{2}{*}{ Stages } & ADP & AP & EP & GWP & ODP & РОСР & ETP & HTP & \multirow{2}{*}{ Sum } \\
\hline & & Sb-eq & $\mathrm{SO}_{2}$-eq & $\mathrm{PO}_{4}{ }^{3-}-\mathrm{eq}$ & $\mathrm{CO}_{2}$-eq & CFC11-eq & $\mathrm{C}_{2} \mathrm{H}_{4}-\mathrm{eq}$ & 1,4DCB-eq & 1,4DCB-eq & \\
\hline \multirow{3}{*}{ HMA } & Construction & $\begin{array}{c}9060 \\
(84.1)\end{array}$ & $\begin{array}{l}4820 \\
(4.4)\end{array}$ & $\begin{array}{l}1580 \\
(4.6)\end{array}$ & $\begin{array}{c}1,500,000 \\
(78.1)\end{array}$ & $\begin{array}{c}0.134 \\
(1.0)\end{array}$ & $\begin{array}{l}1020 \\
(6.4)\end{array}$ & $\begin{array}{c}1080 \\
(143.1)\end{array}$ & $\begin{array}{c}522,000 \\
(37.0)\end{array}$ & $(358.7)$ \\
\hline & Maintenance & $\begin{array}{c}7510 \\
(69.7)\end{array}$ & $\begin{array}{l}3180 \\
(2.9)\end{array}$ & $\begin{array}{l}1280 \\
(3.7)\end{array}$ & $\begin{array}{c}1,210,000 \\
(63.0)\end{array}$ & $\begin{array}{c}0.0922 \\
(0.7)\end{array}$ & $\begin{array}{c}683 \\
(4.3)\end{array}$ & $\begin{array}{c}1080 \\
(143.1)\end{array}$ & $\begin{array}{c}458,000 \\
(32.5)\end{array}$ & (319.9) \\
\hline & Total & $\begin{array}{l}16,570 \\
(153.8)\end{array}$ & $\begin{array}{l}8000 \\
(7.3)\end{array}$ & $\begin{array}{l}2860 \\
(8.3)\end{array}$ & $\begin{array}{c}2,710,000 \\
(141.1)\end{array}$ & $\begin{array}{c}0.2262 \\
(1.7)\end{array}$ & $\begin{array}{c}1703 \\
(10.7)\end{array}$ & $\begin{array}{c}2160 \\
(286.2)\end{array}$ & $\begin{array}{c}980,000 \\
(69.5)\end{array}$ & $(678.6)$ \\
\hline \multirow{3}{*}{ PCC } & Construction & $\begin{array}{l}16,300 \\
(151.2)\end{array}$ & $\begin{array}{l}8210 \\
(7.4)\end{array}$ & $\begin{array}{l}1030 \\
(3.0)\end{array}$ & $\begin{array}{c}4,480,000 \\
(233.3)\end{array}$ & $\begin{array}{c}0.413 \\
(3.0)\end{array}$ & $\begin{array}{l}11,700 \\
(73.8)\end{array}$ & $\begin{array}{c}93 \\
(12.4)\end{array}$ & $\begin{array}{c}2,470,000 \\
(175.2)\end{array}$ & $(659.3)$ \\
\hline & Maintenance & $\begin{array}{c}7200 \\
(66.8)\end{array}$ & $\begin{array}{l}3290 \\
(3.0)\end{array}$ & $\begin{array}{l}1020 \\
(3.0)\end{array}$ & $\begin{array}{c}1,180,000 \\
(61.5)\end{array}$ & $\begin{array}{c}0.0786 \\
(0.6)\end{array}$ & $\begin{array}{l}1050 \\
(6.6)\end{array}$ & $\begin{array}{c}749 \\
(99.3)\end{array}$ & $\begin{array}{c}439,000 \\
(31.1)\end{array}$ & (271.9) \\
\hline & Total & $\begin{array}{l}23,500 \\
(218.0)\end{array}$ & $\begin{array}{c}11,500 \\
(10.4)\end{array}$ & $\begin{array}{l}2050 \\
(6.0)\end{array}$ & $\begin{array}{c}5,660,000 \\
(294.8)\end{array}$ & $\begin{array}{c}0.4916 \\
(3.6)\end{array}$ & $\begin{array}{l}12,750 \\
(80.4)\end{array}$ & $\begin{array}{c}842 \\
(111.7)\end{array}$ & $\begin{array}{c}2,909,000 \\
(206.3)\end{array}$ & (931.2) \\
\hline
\end{tabular}

Note: The numbers in parentheses are weighting values (eco-point) for the characterized values.

The evaluation of the entire life cycle revealed a $27.1 \% \mathrm{P}((931-679) \div 931 \times 100)$ improvement over the PCC pavement in terms of the environmental impact. Among the eight potential impact categories, the most influential items involved in the HMA and PCC are ETP and GWP, which have a total impact of $42.2 \%$ and $31.7 \%$, respectively. This confirms that the item and its total rate, which contribute to the environmental impact associated with these two materials over a 50-year period, are different, as presented in Figure 3.

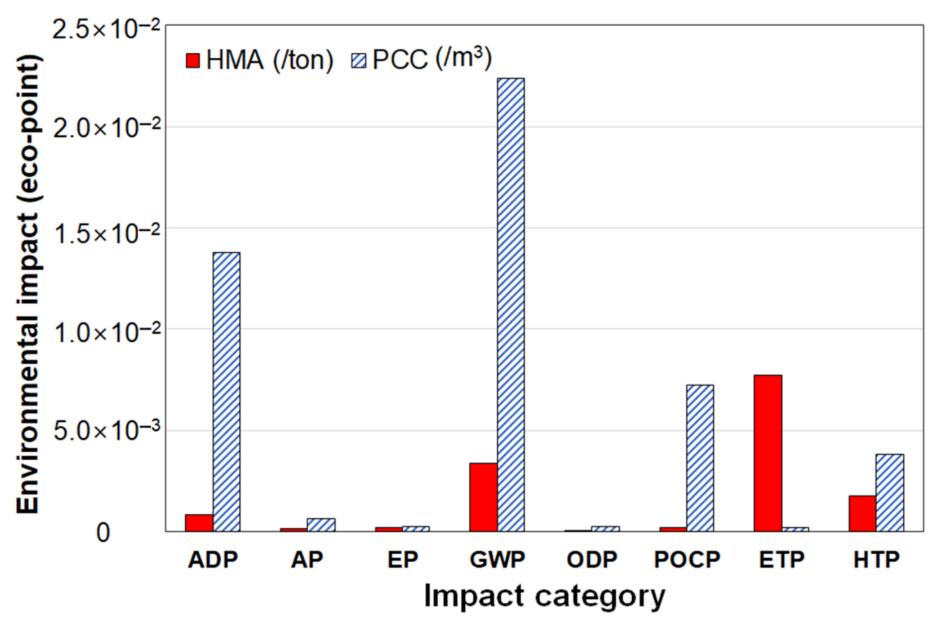

Figure 3. Environmental impact of major materials. 


\subsection{Evaluating the Economic Performance}

The LCC, which presents the ECP indicators, are presented in Table 5. The initial cost for the construction of a four-lane 1-km highway PCC pavement, including the design cost, is $23.3 \%$ P (i.e., $(1321.3-1013.3) \div 1321.3 \times 100)$, which is less than that of the HMA pavement. Over the service life of 50 years, the maintenance cost and the total LCC can be reduced by approximately $15.9 \%$ P (i.e., $(1288.5-1083.5) \div 1288.5 \times 100)$ and $19.7 \%$ P (i.e., $(2609.8-2096.8) \div 2609.8 \times 100)$, respectively. This confirms that the PCC pavement is more favorable compared with the HMA pavement if the economic dimension is considered.

Table 5. LCCA outputs (\$ thousands).

\begin{tabular}{|c|c|c|c|c|c|}
\hline \multirow{2}{*}{$\begin{array}{l}\text { Cycle } \\
\text { (Year) }\end{array}$} & \multirow{2}{*}{$\begin{array}{l}\text { Discount } \\
\text { Factor }\end{array}$} & \multicolumn{2}{|r|}{ HMA Pavement } & \multicolumn{2}{|r|}{ PCC Pavement } \\
\hline & & PV & Event (Repair Rates, \%) & PV & Event (Repair Rates, \%) \\
\hline \multicolumn{2}{|c|}{ Initial Cost } & 1321.3 & & 1013.3 & \\
\hline 5 & 0.880 & 5.2 & Patching (3.3) & - & - \\
\hline 8 & 0.815 & - & - & 14.5 & Crack repair (3.4), Joint repair (13.0) \\
\hline 9 & 0.794 & 271.9 & Cutting \& overlay (100.0) & - & - \\
\hline 10 & 0.774 & 4.6 & Patching (3.3) & 83.2 & Section repair (20.2) \\
\hline 15 & 0.681 & 237.3 & Patching (3.3), Cutting \& overlay (100.0) & 35.2 & Cutting \& overlay (27.2) \\
\hline 16 & 0.664 & - & & 11.8 & Crack repair (3.4), Joint repair (13.0) \\
\hline 20 & 0.600 & 3.6 & & 526.5 & HMA Re-pavement (100.0) \\
\hline 21 & 0.585 & 200.1 & Patching (3.3) & - & - \\
\hline 25 & 0.528 & 3.1 & Cutting \& overlay (100.0) & - & - \\
\hline 26 & 0.514 & - & Patching (3.3) & 8.1 & Patching (4.2) \\
\hline 27 & 0.501 & 171.7 & & - & - \\
\hline 28 & 0.489 & - & Cutting \& overlay (100.0) & 155.7 & Cutting \& overlay (100.0) \\
\hline 30 & 0.464 & 2.8 & & - & 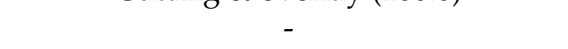 \\
\hline 32 & 0.441 & - & Patching (3.3) & 7.0 & Patching (4.2) \\
\hline 33 & 0.430 & 147.2 & & - & - \\
\hline 35 & 0.409 & 2.4 & Cutting \& overlay (100.0) & - & - \\
\hline 36 & 0.398 & - & Patching (3.3) & 126.9 & Cutting \& overlay (100.0) \\
\hline 38 & 0.378 & - & & 6.0 & Patching (4.2) \\
\hline 39 & 0.369 & 126.3 & & - & - \\
\hline 40 & 0.360 & 2.1 & Cutting \& overlay (100.0) & - & - \\
\hline 44 & 0.325 & - & Patching (3.3) & 108.6 & Patching (4.2), Cutting \& overlay (100.0) \\
\hline 45 & 0.316 & 110.2 & & - & - \\
\hline 50 & 0.279 & - & Patching (3.3), Cutting \& overlay (100.0) & - & - \\
\hline \multicolumn{2}{|c|}{ Repair Cost } & 1288.5 & & 1083.5 & \\
\hline \multicolumn{2}{|c|}{ Total Cost } & 2609.8 & & 2096.8 & \\
\hline
\end{tabular}

\subsection{Computing OPs Using the TOPSIS and BEES Methods}

After the evaluation of the OP using the TOPSIS method and calculation of the SD using Equations (5) and (6), the relative closeness to the ideal solution, which is the OP score, is calculated using Equation (7). The OPs of the HMA and PCC pavements obtained by the TOPSIS method are 0.53 and 0.52 points, respectively, as presented in Figure 4 . By substituting the values of EVP and ECP presented in Table 4; Table 5 with the corresponding variables in Equation (8), the OPs of the HMA and PCC pavements are obtained by the BEES method. These OPs are 48.8 and 51.2 points, respectively, as presented in Figure 5 . Both the TOPSIS and BEES methods confirm that HMA outperforms PCC in terms of the ECP and EVP, as presented in Table 6. 


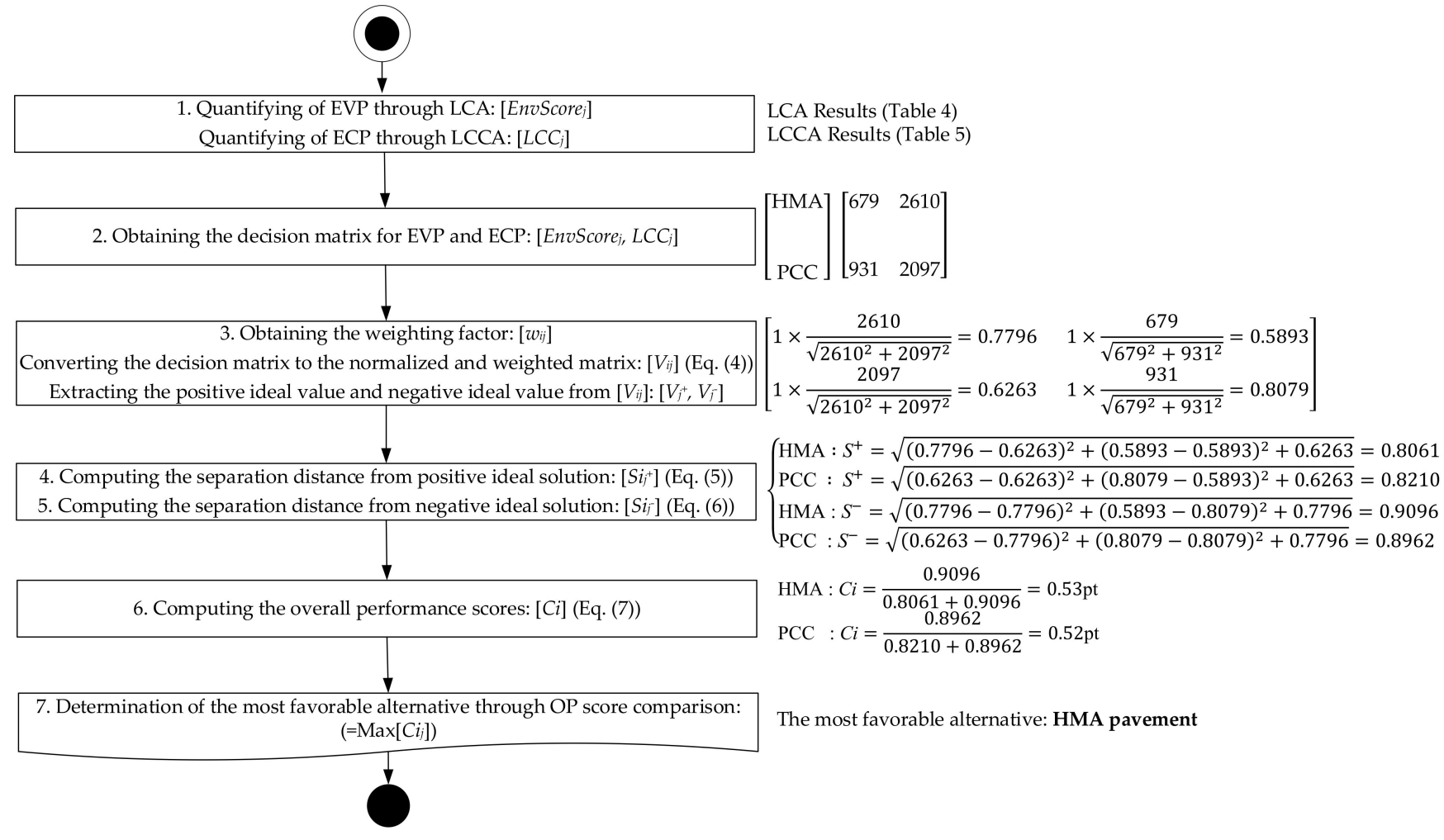

Figure 4. The computation of the overall performance using the TOPSIS method.

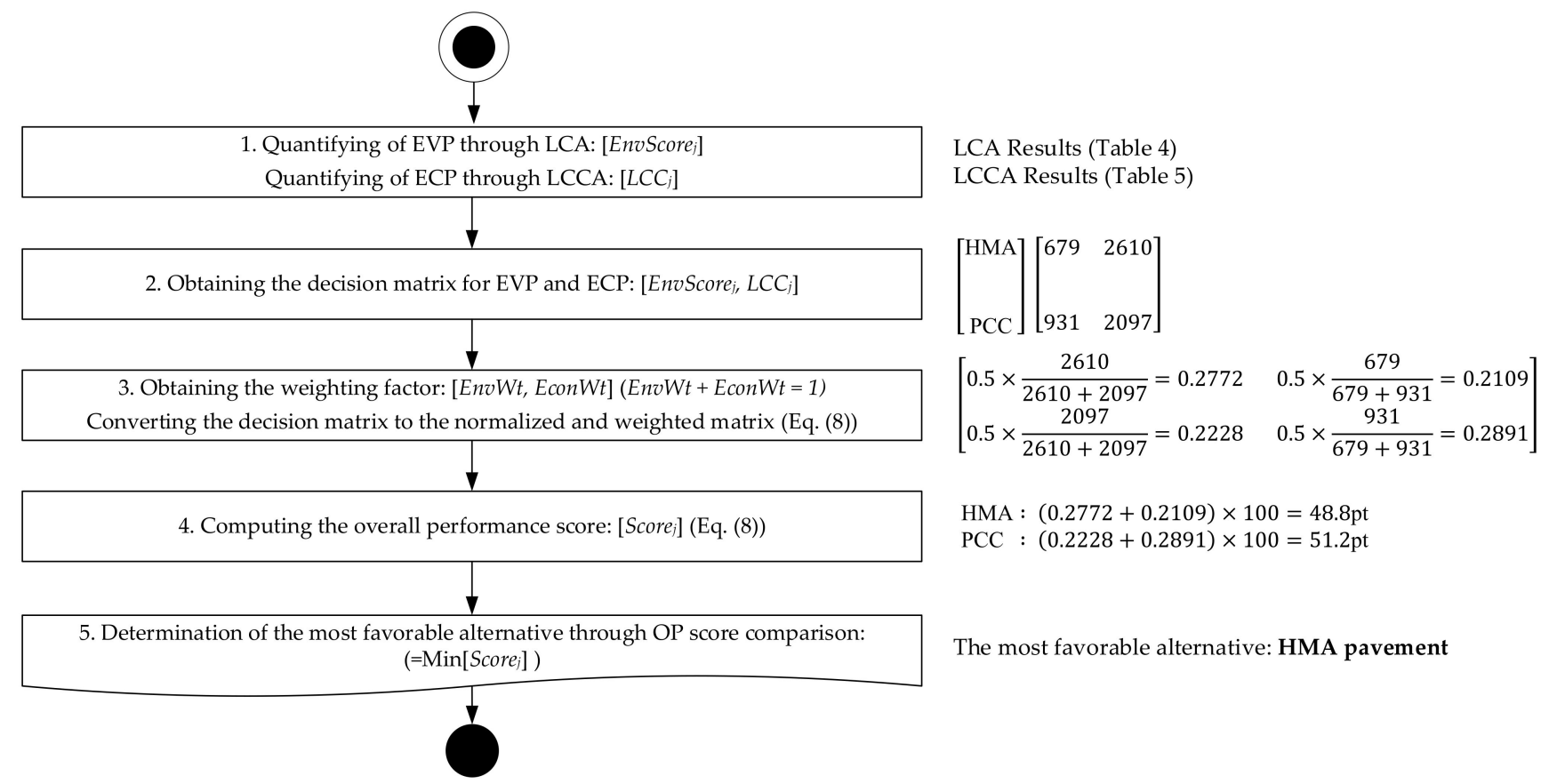

Figure 5. The computation of the overall performance using the BEES method. 
Table 6. Summary of OP assessments.

\begin{tabular}{ccccc}
\hline Performance Index & $\begin{array}{c}\text { HMA } \\
\text { Pavement }\end{array}$ & $\begin{array}{c}\text { PCC } \\
\text { Pavement }\end{array}$ & $\begin{array}{c}\text { Recommended } \\
\text { Solution }\end{array}$ & $\begin{array}{c}\text { Performance } \\
\text { Deviation (\%P) }\end{array}$ \\
\hline EVP from LCA (eco-point) & 679 & 931 & HMA & -27.1 \\
ECP from LCCA (\$ thousands) & 2610 & 2097 & PCC & +19.7 \\
OP Score of the TOPSIS method & 0.53 & 0.52 & HMA & +1.9 \\
OP Score of the BEES method & 48.80 & 51.20 & HMA & -4.7 \\
OP Score of the IBEES method (ECI) & 23.40 & 25.80 & HMA & -9.3 \\
\hline
\end{tabular}

Note: Performance deviation is based on an unselected alternative. In the TOPSIS method, the higher OP score is considered as a superior alternative.

\subsection{Comparative Analysis of the Overall Performance Using the TOPSIS and BEES Methods}

The EVP of the HMA pavement and ECP of the PCC pavement are more favorable than the EVP of the PCC pavement and ECP of the HMA pavement, respectively. After the evaluation of the OPs by the TOPSIS and BEES methods using the EVP and ECP values, the HMA was found to be more favorable, as presented in Table 6. The HMA pavement offers an environmental advantage of $27.1 \% \mathrm{P}$ compared with the PCC pavement; conversely, the PCC pavement offers an economic advantage (i.e., cost saving) of $19.7 \% \mathrm{P}$ compared with the HMA pavement. The deviation of the EVPs obtained by the two pavement materials is considerably larger than that of the ECPs. This confirms that the EVP is the major contributor to the OP score. Indeed, the OP scores obtained by the TOPSIS and BEES methods represent only relative superiority, as presented in Table 6. It is noteworthy that none of the two methods are suitable for the quantification of the extent to which the EVP and ECP are reflected in the OP. Thus, quantification of the performance differences would be desirable rather than simply presenting relative superiority when evaluating the OPs. It may also facilitate in making informed decisions. The quantification of the values of the performance factors (i.e., EVP or ECP) associated with unfavorable alternatives is very critical to the development of environmentally friendly methods or to the improvement of the existing ones, particularly, to the presentation of the target amount for improving the EVP and ECP accurately. These values contribute to the elimination of any waste in time and money due to trial and error.

The superiority of one alternative to the other is determined by measuring the distances between the two alternatives on top of the Euclidean plane formulated by modeling the normalized values of the EVP and ECP using the TOPSIS and BEES methods $[9,37]$. Both methods assume that EVP and ECP have a linear relationship in their values. The ECP of the HMA pavement is $124.4 \%$ of that of the PCC pavement; the EVP of the one is $72.9 \%$ of the ECP of the other. Therefore, these two methods manifest the performance difference of $9.3 \% \mathrm{P}$ in the OP scores. The BEES and TOPSIS methods, as presented in Table 6, calculate the performance difference of $4.7 \% \mathrm{P}$ and $1.9 \% \mathrm{P}$, respectively. The BEES method computes equivalent outputs obtained by the TOPSIS method, as presented in Table 6. The BEES and TOPSIS methods overestimate the performance of the PCC pavement by $4.6 \%$ P (i.e., $9.3 \% \mathrm{P}-\{(51.2-48.8) \div 51.2 \times 100\})$ and $7.4 \% \mathrm{P}($ i.e., $9.3 \% \mathrm{P}-\{(0.53-0.52) \div 0.53 \times 100\})$, respectively; moreover, the two methods underestimate the performance of the HMA pavement. Indeed, a new method that quantitatively evaluates how the EVP and ECP contribute to the OP may complement the limitations of the TOPSIS and BEES methods. The proposed method may provide a beneficial tool either for setting the quantitative targets for environmental and cost impact or for identifying the work packages (or resources) available for the reduction of the environmental and cost impact.

As presented in Figure 6, the IBEES method performs the proposed ECI calculation process for this purpose. The calculation is done by substituting the EI and CI in Equation (11) with the corresponding variables obtained using Equations (9) and (10), respectively. Each ECI is 23.4 and 25.8 points when the HMA and PCC pavements are employed, respectively, to the case projects. The outputs obtained by the IBEES method are equivalent to those obtained by the TOPSIS and BEES methods. All three methods identify 
the HMA as the optimal solution. Note that the OP accrued by the HMA pavement is $9.3 \%$ P (i.e., $(25.8-23.4) \div 25.8 \times 100)$ greater than that by the PCC pavement. This confirms that the deviation between the EVP and ECP is accurately projected to ECI. Moreover, the IBEES method is also confirmed to pass the quantitative and qualitative verification tests using the case data in the Method Verification section. The validation outputs are presented in Table 6. The 86.5 eco-point MCER is computed by substituting the MROP in Equations (12) and (13) with 9.3\%, as presented in Figure 6. The point value is the minimum reduction amount of the environmental impact required to reinstate the ECI accrued by an unfavorable alternative, PCC pavement, to the equivalent ECI achieved by the HMA pavement. When the 86.5 eco-point is reduced from the EVP of the PCC pavement by using eco-friendly materials such as recycled aggregates, the ECIs of the HMA pavement and that of the PCC pavement become 24.71 and 24.70 points, respectively. The best alternative changes from the HMA pavement to the PCC pavement due to the very minimal difference of 0.01 point.

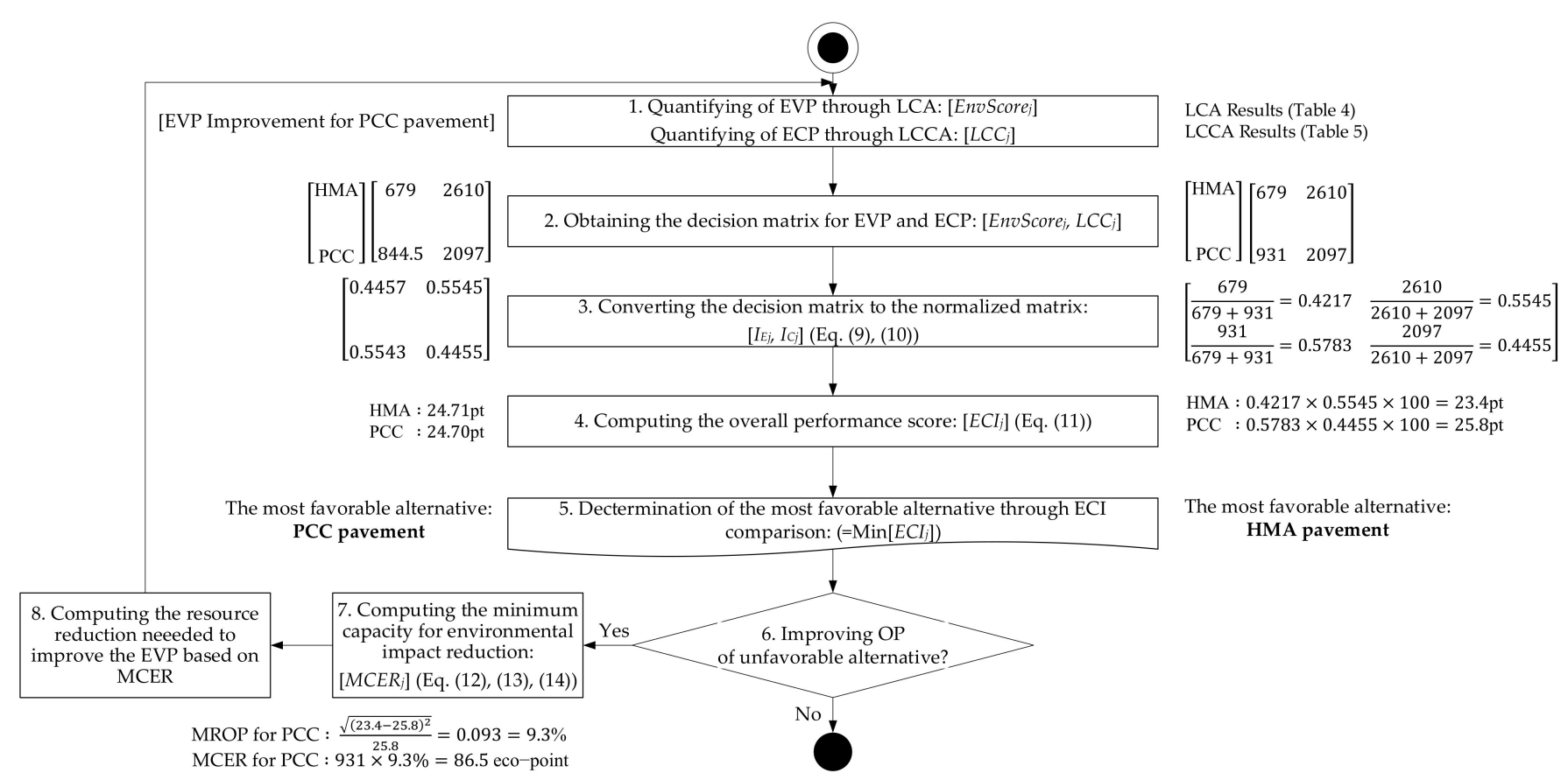

Figure 6. The computation of the overall performance using the IBEES method.

The IBEES method comprehensively covers the information that can be obtained by the TOPSIS and BEES methods when developing eco-friendly construction methods and upgrading the existing ones. Moreover, it effectively implements the MCER and ECI computation processes on top of the existing methods. The MCER and the ECI, which are implemented by the IBEES, provide a means to reduce the EVP of the PCC pavement while assuring to achieve equivalent performance outputs expected from the existing methods (i.e., TOPSIS and BEES). In addition, they provide an integrated platform to assess the EVP and ECP of the candidate pavement materials and methods, respectively. The outputs obtained by this case study may not be considered as new findings as they are more or less in line with the existing studies that evaluate the environmental impact and the economic feasibility of road pavement materials. It is noteworthy that the contribution of the case study is not the fact-finding if a particular construction method (i.e., HMA or PCC) is more favorable than the other but the IBEES decision-making tool itself that accurately evaluates the environmental impact and economic feasibility of a method. Indeed, the IBEES method facilitates in making more informed decisions which cannot be handled by the existing methods. 


\section{Conclusions}

The research findings, which were obtained by performing the LCA and LCCA on the national highway projects in Korea using the maintenance scenarios administered by the KEC in the maintenance stage, are as follows: The LCA outputs confirm that the environmental impact attributed to the HMA is $27.1 \% \mathrm{P}$ smaller than that of PCC; the LCCA outputs confirm that the economic impact attributed to PCC is $19.7 \% \mathrm{P}$ lower than that of HMA. The OPs that were obtained by inputting the LCA and LCCA outputs into the TOPSIS and BEES methods provide admissible evidence that these two methods identify the HMA pavement as the best solution. The OPs of the HMA and PCC pavements, calculated along with the ECI, are 23.4 and 25.8 points, respectively. These outputs provide admissible evidence that the ECI computation proposed recommends the HMA pavement as the best alternative. This indicates that the ECI produces equivalent outputs to the existing methods, thus exhibiting reliability. In addition, it is noteworthy that the existing methods may overestimate the unfavorable alternatives or underestimate the best alternative, as they are not suitable for accurately projecting the EVP and ECP to OP. The admissible evidence is that the difference of the OP of HMA and that of PCC obtained by the TOPSIS method is only $1.9 \% \mathrm{P}$ and that obtained by the BEES method is $4.7 \% \mathrm{P}$. Indeed, the former is considered to be very trivial, whereas the latter is less than the difference of $9.3 \% \mathrm{P}$, which may be expected when assuming linearity between the EVP and ECP. The proposed method addresses these issues by introducing the concept of area on the Euclidean plane in the ECI computation process, thus complementing the existing BEES method. The $\mathrm{ECI}$ accurately projects the linear performance difference between the EVP and ECP (i.e., $9.3 \% \mathrm{P}$ ) to OP. Furthermore, this achievement quantifies the information needed to replace the identified PCC as an unfavorable alternative. These outputs facilitate in setting the EVP (or ECP) target that should be improved to ensure the development of eco-friendly and economically feasible technologies. Indeed, the new contributions of the IBEES is to complement the waste of time and cost accrued by the existing methods which perform trial-and-error until they find the best solution. Thus, it makes the OP characteristics of the alternatives quantitatively crisp. It should be noted that the novelty of the method is justified as no existing method confirms that the PCC pavement may be reinstated to another best alternative if more than 86.5 eco-points (MCER) is reduced. Indeed, the quantitative measure may control the performance of the trade-off of the amount (or the quality) associated with the utilized resources.

The main contribution of this study is the implementation of the IBEES method, which comprehensively hybridizes the MCER and ECI computation processes along with the existing methods (i.e., TOPSIS and BEES). The proposed method enables researchers and practitioners to identify the most favorable alternative pavement material by considering the impacts of the EVP and ECP on the OP. Such method is considered to be an improvement of the existing ones owing to its ability to improve the quality of decision making by considering both the EVP and ECP. Moreover, it evaluates the OP in terms of investment efficiency (i.e., ROI) through the identification of the EVP that can be obtained when an identical cost is invested in all of the alternatives. Indeed, the new method may promote the development of sustainable construction materials and methods by providing crisp OP information.

Author Contributions: Conceptualization, J.-Y.P.; validation, J.-Y.P., B.-S.K. and D.-E.L.; formal analysis, J.-Y.P.; resources, J.-Y.P. and B.-S.K.; writing—original draft preparation, J.-Y.P.; writingreview and editing, D.-E.L.; funding acquisition, J.-Y.P. and D.-E.L. All authors have read and agreed to the published version of the manuscript.

Funding: This research was supported by the National Research Foundation of Korea (NRF) grant funded by the Korea government (MSIT), grant number NRF-2018R1A5A1025137, NRF2019R1C1C1010222.

Institutional Review Board Statement: Not applicable. 
Informed Consent Statement: Not applicable.

Data Availability Statement: The data that include LCA outputs, LCCA outputs and assessment results for overall performance presented in this study are available in the paper.

Conflicts of Interest: The authors declare no conflict of interest.

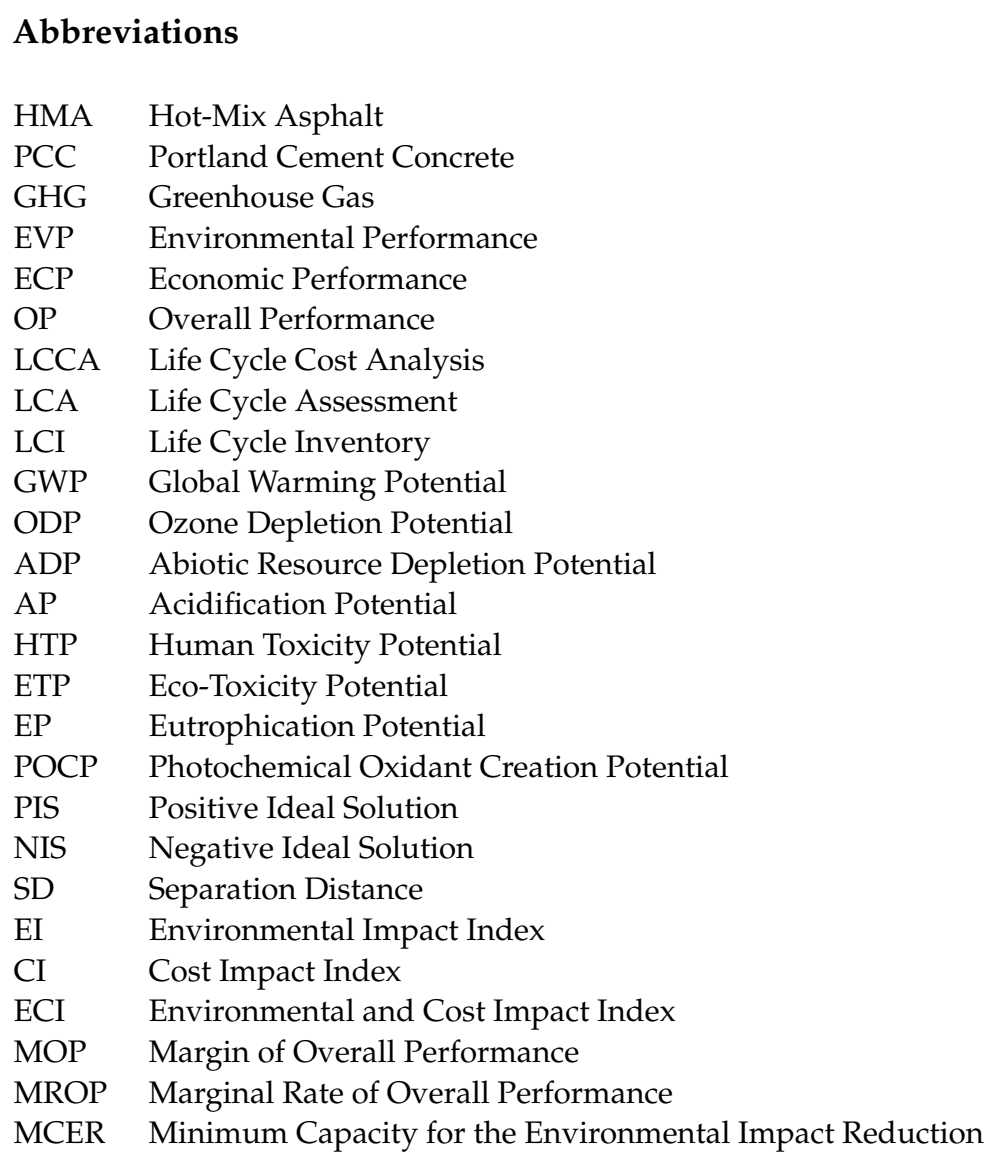

\section{References}

1. MOSF. National Financial Management Plan; Ministry of Strategy and Finance of Korea Government: Seoul, Korea, 2017.

2. Park, J.-Y.; Kim, B.-S. Life-cycle assessment-based environmental impact estimation model for earthwork-type road projects in the design phase. KSCE J. Civ. Eng. 2019, 23, 481-490. [CrossRef]

3. Liu, R.; Smartz, B.W.; Descheneaux, B. LCCA and Environmental LCA for Highway Pavement Selection in Colorado. Int. J. Sustain. Eng. 2015, 8, 102-110. [CrossRef]

4. Nassiri, S.; Bayat, A.; Skirriw, R. Integrated Road Research Facility (IRRF): An Albertan Research Initiative. In Proceedings of the Conference and Exhibition of the Transportation Association of Canada-Transportation: Better-Faster-Safer, Winnipeg, MB, Canada, 22-25 September 2013; Transportation Association of Canada: Ottawa, ON, Canada.

5. Van der Lugt, P.; van den Dobbelsteen, A.A.J.F.; Janssen, J.J.A. An environmental, economic and practical assessment of bamboo as a building material for supporting structures. Constr. Build. Mater. 2006, 20, 648-656. [CrossRef]

6. $\quad$ Elkington, J. Cannibals with Forks: The Triple Bottom Line of 21st Century Business; Capstone Pub.: Oxford, UK, 1997.

7. Umer, A.; Hewage, K.; Haider, H.; Sadiq, R. Sustainability Evaluation Framework for Pavement Technologies: An Integrated Life Cycle Economic and Environmental Trade-off Analysis. Transport. Res. Part. D Transport. Environ. 2017, 53, 88-101. [CrossRef]

8. Sackey, S.; Kim, B.-S. Environmental and economic performance of asphalt shingle and clay tile roofing sheets using life cycle assessment approach and TOPSIS. J. Constr. Eng. Manag. 2018, 144, 04018104. [CrossRef]

9. Lippiatt, B.C. Bees 4.0: Building for Environmental and Economic Sustainability, Technical Manual and User Guide; National Institute of Standards and Technology: Gaithersburg, MA, USA, 2007.

10. Tudora, A.-C. Assessments criteria of building materials from ecological point of view. Bul. Inst. Politeh. Iasi. Sect. Constr. Arhitectura 2011, 57, 129-137.

11. Ma, H.; Zhang, Z.; Zhao, X.; Wu, S. A comparative life cycle assessment (LCA) of warm mix asphalt (WMA) and hot mix asphalt (HMA) pavement: A case study in china. Adv. Civ. Eng. 2019, 2019, 1-12. [CrossRef] 
12. Kwon, S.-H.; Kim, K.J.; Kim, K.; Cho, N. Assessment model on environmental economics for construction projects in Korea. KSCE J. Civ. Eng. 2012, 16, 505-516. [CrossRef]

13. Chan, W.-C. Economic environmental evaluation of life cycle cost analysis practice: A case study of Michigan DOT pavement projects. Master's Thesis, University of Michigan, Ann Arbor, MI, USA, 2007.

14. Li, J.; Xiao, F.; Zhang, L.; Amirkhanian, S.N. Life cycle assessment and life cycle cost analysis of recycled solid waste materials in highway pavement: A review. J. Clean Prod. 2019, 233, 1182-1206. [CrossRef]

15. Zhang, H.; Keoleian, G.A.; Lepech, M.D.; Kendall, A. Life-cycle optimization of pavement overlay systems. J. Infrastruct. Syst. 2010, 16, 310-322. [CrossRef]

16. Hwang, C.-L.; Yoon, K. Multiple Attribute Decision Making-Methods and Application a State-of-the-Art Survey; Springer: Berlin/Heidelberg, Germany, 1981; Volume 186. [CrossRef]

17. Nirmal, D. Environmental and cost impact analysis of materials and assemblies in building construction. Master's Thesis, Florida International University, Miami, FL, USA, 2012. [CrossRef]

18. ISO. Environmental Management_Life cycle Assessment_Principles and Framework; International Organization for Standardization: Geneva, Switzerland, 2006.

19. UNEP. Evaluation of Environmental Impacts in Life Cycle Assessment; United Nations Environment Program: Paris, France, 2003.

20. Jolliet, O.; Müller-Wenk, R.; Bare, J.; Brent, A.; Goedkoop, M.; Heijungs, R.; Itsubo, N.; Penã, C.; Potting, J.; Pennington, D.; et al. The LCIA midpoint-damage framework of the UNEP/SETAC life cycle initiative. Int. J. Life Cycle Assess. 2004, 9, 394-404. [CrossRef]

21. Jang, M.; Hong, T.; Ji, C. Hybrid LCA model for assessing the embodied environmental impacts of building in South Korea. Environ. Impact. Assess. Rev. 2015, 50, 143-155. [CrossRef]

22. Cabeza, L.F.; Rincón, L.; Vilariño, V.; Pérez, G.; Castell, A. Life cycle assessment (LCA) and life cycle energy analysis (LCEA) of buildings and the building sector: A review. Renew. Sust. Energ. Rev. 2014, 29, 394-416. [CrossRef]

23. Liu, C.; Ahn, C.R.; An, X.; Lee, S. Life-cycle assessment of concrete dam construction: Comparison of environmental impact of rock-filled and conventional concrete. J. Const. Eng. Manag. 2013, 139. [CrossRef]

24. Huang, Y.; Bird, R.; Heidrich, O. Development of a life cycle assessment tool for construction and maintenance of asphalt pavements. J. Clean Prod. 2009, 17, 283-296. [CrossRef]

25. KEC. Integrated Management of Life Cycle Cost (LCC) DB Using Maintenance Big Data-LCC Guidelines; Korea Expressway Corporation: Gimcheon-si, Korea, 2015.

26. The Ecoinvent Organisation. Available online: http:/ / www.ecoinvent.org/ (accessed on 1 November 2015).

27. Korea Environmental Industry and Technology Institute. Korea LCI Database Information Network. Available online: http: / /edp.or.kr/lci/lci_db.asp/ (accessed on 1 January 2019).

28. Yi, S.; Kurisu, K.H.; Hanaki, K. Application of LCA by using midpoint and endpoint interpretations for urban solid waste management. J. Environ. Prot. 2014, 5, 1091-1103. [CrossRef]

29. ME (Ministry of Environment). Korean Environmental Impact Assessment Index Methodology; Ministry of Environment of Korea Government: Seoul, Korea, 2003.

30. Reap, J.; Roman, F.; Duncan, S.; Bras, B. A survey of unresolved problems in life cycle assessment. Int. J. Life Cycle Assess. 2008, 13, 374-388. [CrossRef]

31. Arditi, D.; Messiha, H.M. Life cycle cost analysis (LCCA) in municipal organizations. J. Infrastruct. Syst. 1999, 5, 1-10. [CrossRef]

32. Shil, N.; Mahbub, P. Life cycle costing: An alternative selection tool. Univ. Libr. Munich MPRA Pap. 2007, 9, 49-68.

33. The Bank of Korea. Economic Statistics System. Available online: http:/ / ecos.bok.or.kr/ (accessed on 1 February 2019).

34. Santos, J.; Flintsch, G.; Ferreira, A. Environmental and economic assessment of pavement construction and management practices for enhancing pavement sustainability. Resour. Conserv. Recyc. 2017, 116, 15-31. [CrossRef]

35. Anupam, K.; Lal, P.S.; Bist, V.; Sharma, A.K.; Swaroop, V. Raw material selection for pulping and papermaking using TOPSIS multiple criteria decision making design. Environ. Prog. Sustain. Energy 2013, 33, 1034-1041. [CrossRef]

36. Jato-Espino, D.; Castillo-Lopez, E.; Rodriguez-Hernandez, J.; Canteras-Jordana, J.C. A review of application of multi-criteria decision making methods in construction. Autom. Constr. 2014, 45, 151-162. [CrossRef]

37. Srikrishna, S.; Screenivasulu, R.A.; Vani, S. A new car selection in the market using TOPSIS technique. Int. J. Eng. Res. Gen. Sci. 2014, 2, 177-181. 